\title{
$\mathrm{RDC}$
}

\section{MOVIMENTOS SOCIAIS NA OCUPAÇÃO DE IMÓVEIS VAZIOS NAS ÁREAS CENTRAIS E O ENFRENTAMENTO INCLUSIVO DAS MUDANÇAS CLIMÁTICAS: OS CASOS DE SÃO PAULO E NATAL}

Social Movements on the Occupation of Urban Voids in Central Areas and the Inclusive Facing of Climate Change: The Cases of São Paulo and Natal

\section{Emanuel Ramos Cavalcanti}

Universidade Federal do Rio Grande do Norte - UFRN, Natal, RN, Brasil.

Lattes: http://lattes.cnpq.br/ 6805137553894905 Orcid: https://orcid.org/0000-0002-3131-7786

E-mail: emanuel.cavalcanti.au@gmail.com

\section{Amíria Bezerra Brasil}

Universidade Federal do Rio Grande do Norte - UFRN, Natal, RN, Brasil.

Lattes: http://lattes.cnpq.br/ 8887892378979463 Orcid: https://orcid.org/0000-0001-6877-4916

E-mail: amiriabrasil@gmail.com

\section{Ricardo de Sousa Moretti}

Universidade Federal do ABC, Santo André, SP, Brasil

Lattes: http://lattes.cnpq.br/7819421851048499 Orcid: https://orcid. org/0000-0002-3807-4684

E-mail: ufabc.moretti@gmail.com

\section{Julia Azevedo Moretti}

Pontifícia Universidade Católica de São Paulo (PUC/SP), São Paulo, SP, Brasil Lattes: http://lattes.cnpq.br/ 4735094906899872 Orcid: https://orcid.org/0000-0003-4898-1824 E-mail: moretti.julia@gmail.com

Trabalho enviado em 10 de setembro de 2020 e aceito em 14 de maio de 2021

\section{(c) (i)}

This work is licensed under a Creative Commons Attribution 4.0 International License. 


\section{RESUMO}

Os movimentos populares pela habitação têm desafiado o padrão excludente da urbanização brasileira. As ocupações de imóveis vazios, pelos movimentos sociais, têm pressionado o Estado pelo seu dever de garantir o direito à cidade, inclusive à moradia. As mudanças climáticas tendem a acentuar riscos relacionados à urbanização excludente e seu enfrentamento, inclusivo, ensejaria ações mitigatórias ou adaptativas, corrigindo desigualdades estruturantes e superando vulnerabilidades. $\mathrm{O}$ artigo objetivou destacar as dimensões da vulnerabilidade e da desigualdade, bem como o papel dos movimentos sociais na denúncia de processos desiguais e na construção de alternativas habitacionais, utilizando imóveis ociosos das áreas centrais. Para tanto, partiu-se da premissa da justiça climática, que destaca um problema de justiça social no cerne das questões das mudanças climáticas e, como método, uma análise comparativa entre a dinâmica da urbanização e práticas insurgentes recentes de movimentos sociais, em São Paulo e Natal. Verificou-se que a atuação dos movimentos no uso alternativo de imóveis ociosos em áreas centrais mostrou-se alinhada com o enfrentamento inclusivo das mudanças climáticas. No entanto, persistem dificuldades como no impasse quanto às medidas de melhoria da segurança e qualificação dos edifícios ocupados e na efetivação do direito à cidade, com acesso à moradia e infraestrutura.

Palavras-chave: Direito à cidade; Vazios urbanos; Movimentos sociais; Mudanças climáticas; Justiça climática

\section{ABSTRACT}

Popular housing movements have been challenging the Brazilian's exclusionary pattern of urbanization. Occupations of vacant buildings by social movements constrain the State to guarantee the right to the city, including housing. Climate change accentuates risks related to exclusionary urbanization and responses to its impacts demand mitigation and adaptation measures that support transformations tackling structural inequalities and helping to overcome vulnerabilities. The article aimed to highlight the dimensions of vulnerability and inequality, as well as the role of social movements in denouncing unequal processes and creating housing alternatives, using vacant buildings in central areas. To this purpose, we started from the premise of climate justice which highlights a social justice problem at the heart of climate change issues and performed a comparative analysis between urbanization dynamics and recent insurgent practices of social movements in São Paulo and Natal. It was found that the use of vacant properties in central areas promoted by social movements is aligned with the inclusive confrontation of climate change. However, difficulties persist such as a deadlock situation regarding measures to improve the safety and qualify the use of occupied buildings as well as to implement the right to the city comprising access to housing and infrastructure.

Keywords: Right to the city; Urban voids; Social movements; Climate change; Climate justice. 


\section{INTRODUÇÃO}

As estratégias de movimentos sociais para a afirmação do direito constitucional de moradia (art. 6ㅇ, CF), em São Paulo e Natal, acontecem num momento de ampliação do debate sobre o papel das cidades no enfrentamento das mudanças climáticas e de preocupação crescente com a obtenção de respostas aos efeitos negativos dessas mudanças em um contexto de pobreza e informalidade urbanas. A pandemia do novo coronavírus escancarou desigualdades estruturantes e reforçou que o enfrentamento de crises globais passa pela necessidade de moradia adequada para a população mais vulnerável socioeconomicamente.

A hipótese deste artigo é que a atuação dos movimentos sociais para viabilizar o uso de imóveis ociosos (vazios, subutilizados ou não utilizados) em áreas centrais converge com a abordagem inclusiva para enfrentamento das mudanças climáticas, já que, entre outros fatores, pressionaria pelo aumento da oferta de moradia em áreas centrais, questionando um modelo de crescimento urbano periférico, que põe pressão sobre áreas verdes ou, ainda, gera aumento dos deslocamentos e gastos energéticos com as consequências ambientais associadas. Porém, tal atuação tem enfrentado muitas dificuldades: desde uma lenta implementação (e rápido desmonte) de políticas urbanas voltadas ao uso de imóveis ociosos, para que se cumpra sua função social, até constantes iniciativas para a criminalização desses movimentos sociais.

A partir de uma análise comparativa entre a dinâmica de ocupação ${ }^{1}$ urbana e práticas insurgentes recentes de movimentos sociais em São Paulo e Natal, o presente artigo lança mão do conceito de justiça climática para destacar a dimensão da vulnerabilidade e da desigualdade, bem como o papel dos movimentos sociais na denúncia de processos desiguais e construção de alternativas para produção de moradia social, utilizando imóveis ociosos das áreas centrais, iniciativas que podem ser vistas como forma de enfrentamento inclusivo das mudanças climáticas, fazendo valer o direito à cidade.

Para tanto, o artigo se estrutura em quatro partes: uma primeira, conceitual, na qual se discutem os conceitos de vulnerabilidade e justiça climática no contexto do enfrentamento inclusivo das mudanças climáticas e construção de cidades resilientes, bem como o papel da utilização de imóveis ociosos situados nas áreas centrais das cidades como uma das estratégias nesse processo. $\mathrm{Na}$ segunda parte apresenta-se um resgate das ações coletivas empreendidas pelos movimentos sociais por moradia localizada em áreas urbanas centrais da cidade de São Paulo, com destaque para o processo recente de discussão sobre qualificação gradativa de segurança e de constituição de parcerias 
público-popular, como estratégias para viabilização da permanência dos moradores nos cerca de 50 edifícios ocupados na área central da cidade. Na terceira parte discute-se o processo de expansão urbana na cidade de Natal, apresentando iniciativas recentes de movimentos sociais que têm se empenhado para assegurar a ocupação com fins de moradia de imóveis públicos ociosos localizados nas áreas centrais da cidade, numa estratégia de confluência e articulação entre as pautas de provisão de equipamentos coletivos para população em situação de rua e movimentos sociais de moradia e acesso à cidade. Na quarta e última parte, notas conclusivas apontam aspectos comuns dos dois casos, trazendo uma reflexão sobre o papel que os movimentos sociais vêm desempenhando na busca da ampliação da utilização dos imóveis ociosos nas áreas centrais, sinalizando novos estudos acadêmicos que possam contribuir para esse processo.

\section{O PAPEL dA UTILIZAÇÃo de IMÓVEIS OCIOSOS DE ÁREAS CENTRAIS NO ENFRENTAMENTO INCLUSIVO DAS MUDANÇAS CLIMÁTICAS}

\subsection{JUSTIÇA CLIMÁTICA E O ENFRENTAMENTO INCLUSIVO DAS MUDANÇAS NO CLIMA}

A questão urbana tem merecido um crescente destaque no debate sobre mudanças climáticas e há cada vez mais evidências sobre a relevância das cidades no que concerne aos impactos das mudanças no clima e respostas aos efeitos dessas mudanças. Nesse sentido, o próprio Painel Intergovernamental sobre Mudanças Climáticas (IPCC) tem dedicado cada vez mais espaço para questões urbanas (DODMAN; ARCHER; SATTERTHWAITE, 2019).

Para colocar as cidades no centro do debate, bastaria lembrar que a população mundial e brasileira já é majoritariamente urbana e que as cidades têm alto consumo energético e emissão de gases de efeito estufa (GEE). Com isso também se valoriza sua influência política e a capacidade de liderança para tratar da governança climática urbana, lembrando-se dos crescentes movimentos de articulação de governos locais (MARTINS; FERREIRA, 2011).

Mas no contexto de pobreza, informalidade e desigualdade, que marca o processo de urbanização brasileira (e também de muitas outras cidades no sul global), é fundamental que o enfrentamento das mudanças climáticas se dê a partir de uma perspectiva inclusiva, com vistas à diminuição de riscos e vulnerabilidades da população mais pobre (DODMAN; ARCHER; SATTERTHWAITE, 2019; WILLIANS et al., 2019). As mudanças climáticas tendem a acentuar riscos 
existentes associados a um padrão excludente de urbanização ${ }^{2}$. Assim, a questão climática pode ser vista como oportunidade para, por meio de medidas de mitigação e, principalmente, adaptação, corrigir desigualdades estruturantes e superar vulnerabilidades ${ }^{3}$ e problemas urbano-ambientais atrelados ao padrão de urbanização brasileiro (MARTINS; FERREIRA, 2011).

Ainda assim, o que se percebe é uma situação paradoxal em vários estudos sobre mudanças climáticas. Diagnósticos identificam, ainda que sutilmente, padrões de desigualdade, mas nas ações sugeridas para mitigação e adaptação a desigualdade e práticas inclusivas não são abordadas. Há uma fé na tecnologia eficiente e limpa, em soluções que passam por incentivos ao mercado ${ }^{4}$. Assim, podese dizer que há uma necessidade urgente de ampliar estudos que evidenciem o enfrentamento inclusivo das mudanças climáticas.

Quando se trata de mitigação, a questão central é a redução de emissões e a ampliação de sumidouros com o intuito de limitar a mudança do clima, barrar o aquecimento global. Em áreas urbanas essa questão é traduzida em ações direcionadas às principais fontes de emissão, como padrão energético, transporte e gestão de resíduos sólidos. Já a adaptação trata de ação focalizada num certo sistema vulnerável para atenuar impactos e reduzir danos considerando o cenário atual e futuro ${ }^{5}$. As duas dimensões não podem ser vistas como mutuamente excludentes, mas complementares (MARTINS; FERREIRA, 2011) e em ambas é possível adotar uma perspectiva inclusiva em face das mudanças climáticas, ainda que na adaptação, até mesmo em função do conceito de vulnerabilidade, essa dimensão de justiça social seja mais evidente.

A vulnerabilidade é definida pelo próprio IPCC como propensão ou predisposição a ser afetado adversamente, conceito que envolve outros elementos como suscetibilidade a danos e falta de capacidade de lidar e se adaptar (IPCC, 2014, p. 5). Importa também observar que a vulnerabilidade abrange aspectos sociais, econômicos, políticos e biofísicos (WILLIANS et al., 2019).

A vulnerabilidade é aspecto central em vários estudos que tratam as mudanças climáticas a partir de um viés inclusivo. Relacionando-a com risco e resiliência (tida como antônimo da vulnerabilidade) e buscando alternativas propositivas que envolvam a população atingida no processo de tomada de decisão (WILLIANS et al., 2019) coloca-se em prática a noção de direito à cidade. Isso porque, vale lembrar, o direito à cidade tem uma chave de leitura prático-reivindicativa (TAVOLARI, 2016) que pode fomentar ações climáticas mais inclusivas, abrangendo o impacto do clima no conjunto de outros direitos entendidos como componentes centrais do direito à cidade, quais sejam, função social da terra, sustentabilidade ambiental, gestão democrática, proibição de retrocesso, direito à moradia adequada, acesso ao espaço público (ALFONSIN et al., 2017). A relação entre direito à cidade, 
vulnerabilidade e mudanças climáticas já aparece nos relatórios do IPCC que defende que a redução de déficits de serviços básicos, a melhoria das condições de habitação e a construção de sistemas de infraestrutura resilientes podem reduzir significativamente a vulnerabilidade e a exposição nas áreas urbanas (IPCC, 2014, p. 18).

Estudos empíricos que evidenciam a ligação entre pobreza e vulnerabilidade no contexto das mudanças climáticas mostram que a falta de serviços públicos e infraestrutura provida pelo Estado perpetua o ciclo de pobreza, vulnerabilidade e desigualdade e os esforços comunitários empreendidos para fazer frente aos impactos negativos de eventos climáticos extremos podem até surtir efeito na retomada das condições de vida anteriores a ocorrência de um desastre, mas não são suficientes para promover melhorias significativas na qualidade de vida. Em outras palavras, a resiliência a fenômenos climáticos deve ser entendida a partir de dois aspectos: retomada de condições anteriores (bounce back) e melhoria das condições de vida com superação dos déficits (bounce forward), sendo que nesse segundo quesito a intervenção do Estado por meio de políticas públicas é fundamental (WILLIANS et al., 2019).

Importa observar que a construção da resiliência em face da mudança climática, pressupõe entender a dependência mútua de aspectos ambientais, políticos e socioeconômicos (WILLIANS et al., 2019). Essa interface é notória no movimento de justiça ambiental, que foi pioneiro em destacar a dimensão das desigualdades em questões ambientais.

O movimento da justiça ambiental tem origem na década de 1960 nos Estados Unidos no contexto de denúncias contra a contaminação tóxica e o racismo ambiental, ou seja, casos de distribuição desigual de riscos ambientais e discriminação institucionalizada contra determinados grupos, relacionando raça, pobreza e poluição (CALGARO; RECH, 2017). Importa destacar que a emergência dessa "agenda submersa" (ACSELRAD, 2002), que articula demandas de caráter social, territorial, ambiental e de direitos civis, e que ganhou legitimidade no espaço público, é feita a partir da combinação de conflitos sociais e produção de conhecimento, uma vez que "o conhecimento científico foi correntemente evocado pelos que pretendem reduzir as politicas ambientais à adoção de meras soluções técnicas, o movimento de justiça ambiental estruturou suas estratégias de resistência recorrendo de forma inovadora à própria produção de conhecimento" (ACSELRAD, 2002, p. 53). Tratase, na visão de Henri Acselrad (2002), de uma combinação de momentos subjetivistas e objetivistas em que ao confronto de forças em termos práticos (momento objetivista), por exemplo, conflitos territoriais e locacionais, associa-se a produção de conhecimento que possa ter impacto na construção 
de discursos e representações, inclusive científicas, da realidade (momento subjetivista). Ressalta-se, assim, a importância das ações coletivas protagonizadas pelos movimentos sociais.

Com efeito, a exposição diferenciada ao risco remete à ideia de injustiça ambiental, termo consagrado para destacar as diferenças impostas aos grupos sociais com menos recursos financeiros, políticos e informacionais no que diz respeito à exposição a riscos ambientais (ACSELRAD; MELLO; BEZERRA, 2009).

A justiça climática pode ser vista como uma das vertentes, uma especialização temática da justiça ambiental que destaca um problema de justiça social no cerne da questão sobre mudanças climáticas, afinal "as consequências ambientais decorrentes das alterações climáticas não são suportadas na mesma proporção por todas as parcelas da população" (RAMMÊ, 2012, p. 371).

Vale observar que o tema das mudanças climáticas tem base normativa nacional (Lei № 12.187/2009) e a imperiosa necessidade de dialogar com o planejamento urbano vem ganhando espaço, mas a inclusão do tema em Planos Diretores ainda se dá lentamente, com menções e contribuições indiretas, de natureza mais principiológica (APPOLARO; ALVIM, 2017; ESPÍNDOLA; RIBEIRO, 2020). O enfrentamento inclusivo das mudanças climáticas é abordado de forma tímida na lei federal, que trata apenas de inserir entre as finalidades da Política Nacional sobre Mudanças do Clima a necessidade de compatibilizar desenvolvimento econômico e social com proteção do sistema climático (art. 4ํㅡ, I, Lei ํo 12.187/09), bem como harmonizar as políticas climáticas com o desenvolvimento sustentável a fim de buscar o crescimento econômico, a erradicação da pobreza e a redução das desigualdades sociais (art. 4ํ, parágrafo único, Lei no 12.187/09), reconhecendo ainda nas medidas de adaptação a necessidade de reduzir vulnerabilidades, inclusive as sociais e econômicas (art. 2ํ, I, Lei № 12.187/09). Porém, a perspectiva inclusiva não encontra bases sólidas de operacionalização nos instrumentos de planejamento e financeiros previstos no Decreto no 9.578/18. Em que pese uma alteração recente (Decreto no 10.143/19) ter incluído questões urbanas sensíveis a desigualdades, como saneamento e mobilidade, entre as prioridades do Fundo do Clima, a gestão de recursos do fundo foi centralizada no governo federal e em confederações que representam interesses da indústria, comércio e agricultura, retirando-se da composição do Comitê Gestor do Fundo os representantes de ONGs, da comunidade científica, assim como representantes dos trabalhadores urbanos e rurais (art. 14, II do Decreto 9.578/18, com redação dada pelo Decreto no 10.143/19). 


\subsection{O IMPACTO DO ESPRAIAMENTO DA OCUPAÇÃO URBANA E DA NÃO UTILIZAÇÃO DE} IMÓVEIS NAS ÁREAS CENTRAIS

É certo que, pela perspectiva da mitigação, a redução de emissões de GEE é central para combater as mudanças climáticas. O Inventário sobre Emissões de Gases de Efeito Estufa do Município de São Paulo de $2017^{6}$ indica que a principal fonte emissora é o transporte, ou seja, um modelo de deslocamento baseado em modos de transporte motorizado, muito frequentemente de forma individual, além de contrariar as diretrizes da Lei da Política Nacional da Mobilidade Urbana (art. 6ํ, II, Lei no 12.587/12), gera altos índices de queima de combustíveis fósseis e aumento da emissão de GEE.

As medidas de mitigação e adaptação devem ser vistas como complementares (MARTINS; FERREIRA, 2011) e a questão das fontes de emissão tem nítido ponto de contato com a demanda de habitação em áreas centrais quando se considera o contexto de urbanização periférica, desigual e excludente associada a uma forte matriz rodoviarista sob pneus. Dados da pesquisa Origem-Destino (OD) 2017 (METRÔ, 2019) dão conta de um aumento da frota motorizada particular em proporções muito maiores do que o aumento populacional: enquanto a frota de automóveis particulares aumentou $22,8 \%$ entre 2007 e 2017 o aumento da população foi de 6,6\%. Por outro lado, quando se cruza o modo de viagem com a faixa de renda (Figura 1), fica evidente que a população de baixa renda faz uso de viagens motorizadas coletivas e viagens não motorizadas ${ }^{7}$. Já a população de maior renda utiliza predominantemente formas motorizadas individuais.

Ora, se as viagens coletivas demoram, em média 3 vezes mais do que as viagens individuais (METRÔ, 2019) e os empregos estão concentrados nos distritos centrais (Figura 2), é claro que a população pobre fica mais tempo exposta à poluição para percorrer grandes trechos de deslocamento em transporte coletivo - quem menos contribui, mais sofre, seja com o tempo despendido, com os acidentes de trânsito ou com a exposição à poluição. 
Figura 1 - Viagens por modo e renda familiar

\section{VIAGENS MOTORIZADAS E NÃO MOTORIZADAS POR FAIXA DE RENDA FAMILIAR - 2007 e 2017}

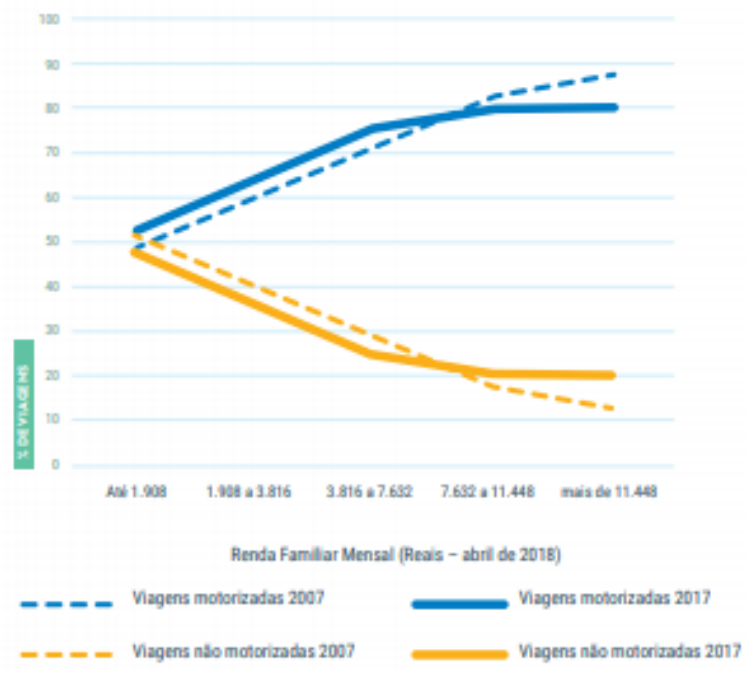

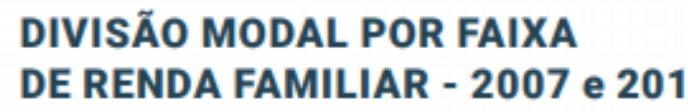

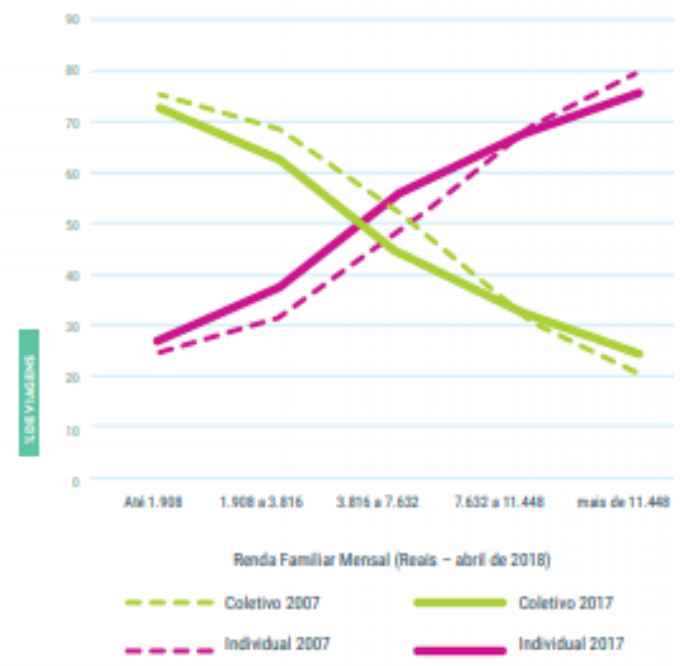

Fonte: Pesquisa Origem-Destino 2017 (METRÔ, 2019).

Figura 2 - Distribuição desigual de emprego no território - São Paulo

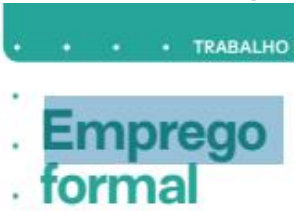

Taxa de emprego formal, por dez

habitantes participantes da PIA

(populaçâo em idade ativa) com idade

igual ou superior a quinze anos $(\%)$
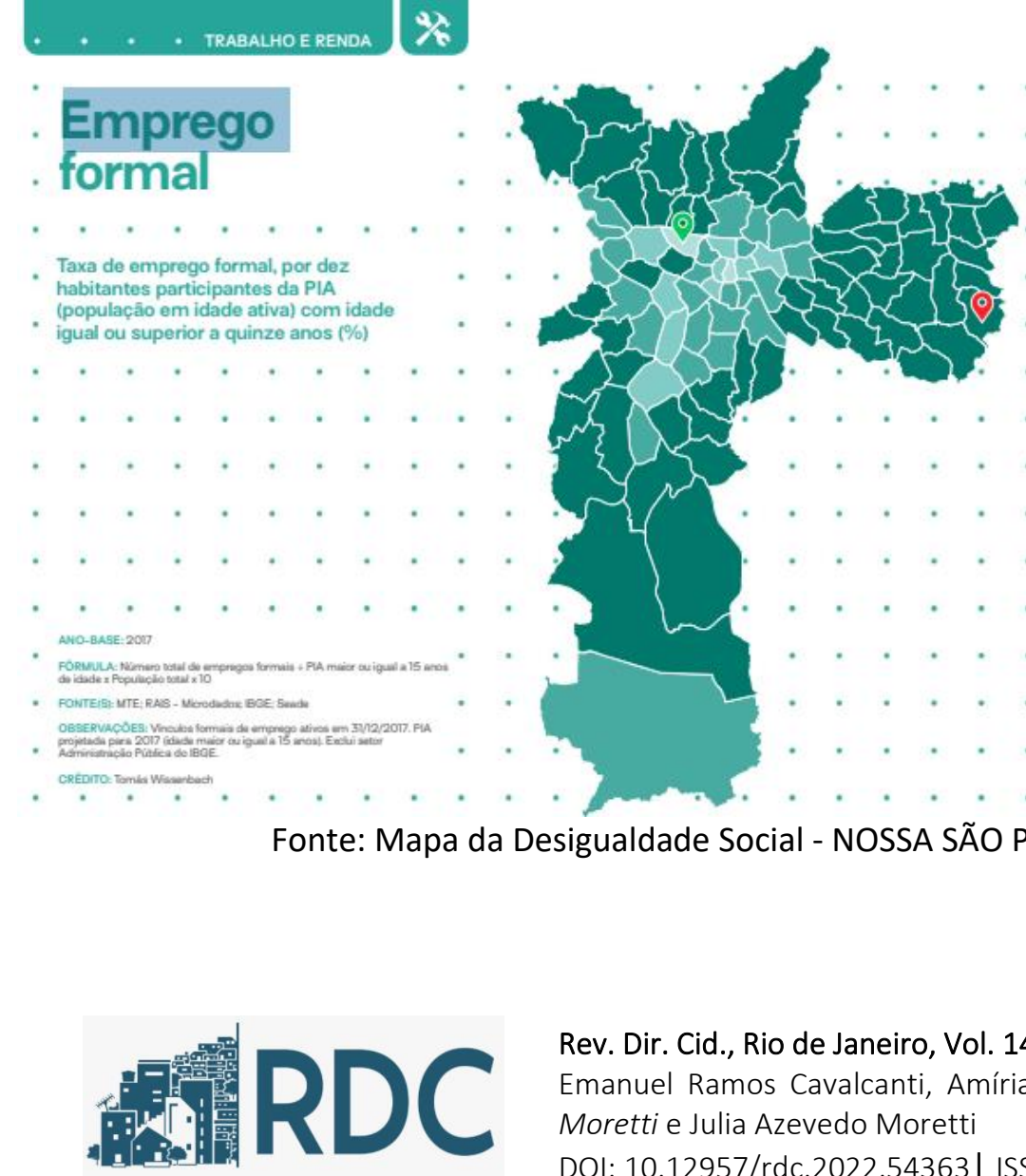

MELHOR/PIOR VALOR

59,2

Barra Funda

0,2

Cidade Tiradentes

6,7

Média da cidade

DESIGUALTÔMETRO

$247 x$

Rev. Dir. Cid., Rio de Janeiro, Vol. 14, N.01., 2022, p. 138 - 169.

Emanuel Ramos Cavalcanti, Amíria Bezerra Brasil, Ricardo de Sousa Moretti e Julia Azevedo Moretti

DOI: 10.12957/rdc.2022.54363| ISSN 2317-7721 
Nesse contexto, a mobilidade e os transportes atuam como sistemas estruturadores das relações socioespaciais de habitação e de trabalho, ou seja, estar (ou almejar estar) inserido/próximo das opções de habitação e trabalho alimentadas pelos sistemas de transportes é fundamental para a inserção na metrópole - fruto da urbanização dispersa/espraiamento. Além disso, como estes sistemas e a mobilidade são os principais orientadores da lógica de valorização imobiliária, a expulsão dos mais pobres das regiões mais acessíveis é fato corrente, como ocorre em São Paulo (ZANDONADE; AUTOR, 2012). Cria-se, assim, um descompasso entre os lugares de habitação e os de emprego: as áreas centrais com grande densidade de empregos e baixa densidade habitacional em contraste com as periferias distantes e menos adensadas (ZANDONADE, 2012). Ao final, há diferentes níveis de acesso à cidade, pois "quem tem mais renda, mora nos lugares mais estratégicos, paga o valor gerado pela acessibilidade, e se desloca com maior velocidade. Quem tem menos renda, se desloca de forma mais devagar e de forma mais precária e desconfortável" (ZANDONADE; AUTOR, 2012, p. 95-96).

Além disso, quando olhamos para a relação entre mobilidade urbana e utilização energética, constatamos que a escolha pelo transporte individual/particular, motorizado, apresenta significativo consumo de espaço e tempo, com grande demanda energética (humana e combustível fóssil), aumento dos congestionamentos, poluição, mortalidade e, principalmente, como contribuinte da urbanização dispersa, em especial, na forma da metropolização (ZANDONADE, 2012).

O enfrentamento inclusivo das mudanças climáticas pressupõe cidades mais justas, compactas, com maior eficiência energética, o que exige, dentre outras, menos deslocamentos e mais habitação nas áreas centrais e em suas expansões imediatas, próximo aos empregos. Tais estratégias são explicitamente indicadas na lei paulistana de mudança do clima (Lei Municipal no 14.933/09) que, no tocante ao uso e ocupação do solo, "dispõe que a sustentabilidade da distribuição da população ao ocupar o território deve ser norteada pelo Princípio da Cidade Compacta" (SOUZA; SOTTO, 2012, p. 329). A adoção destes paradigmas e de ações por estes inspiradas (políticas públicas, planejamento e projetos) poderiam impactar positivamente no combate à urbanização dispersa/espraiamento que, dentre outros efeitos, atua na transformação de áreas rurais em urbanas com grande impacto no meio ambiente (impermeabilização) e na subutilização da infraestrutura existente disponível o que gera o contrassenso da urbanização de áreas ainda não dotadas de infraestrutura, nas distantes periferias, em detrimento da urbanização nas áreas já infraestruturadas ou em vias de serem urbanizadas. 
Ação fundamental na discussão sobre a cidade compacta e combate à urbanização dispersa é a utilização dos imóveis ociosos (vazios, não utilizados ou subutilizados). Nas áreas centrais das metrópoles brasileiras, mas também em níveis urbanos menores, há visivelmente um estoque sem uso ou subutilizado de imóveis, especialmente, edificações vazias, o que contrasta com o déficit habitacional. Na cidade de São Paulo, por exemplo, há estudos elaborados a partir de dados censitários mostrando que a retomada de crescimento de alguns distritos centrais reflete um processo complexo e heterogêneo no interior das metrópoles (MARQUES; REQUENA, 2013). Assim, apesar de não ser possível mais estabelecer uma correlação direta entre crescimento demográfico, renda média e localização - com crescimento das fronteiras urbanas, em locais com menor acesso a infraestrutura e população com rendimentos baixos, contraposta ao esvaziamento de áreas centrais consolidadas e habitadas por população de mais alta renda - as trajetórias demográficas mostram a "permanência dos elevados padrões de segregação presentes na cidade" (MARQUES; REQUENA; 2013, p. 28). Dessa forma, os conflitos locacionais, ou seja, a disputa por um lugar mais bem localizado, por uma infraestrutura instalada, por serviços e empregos, enfim, a reivindicação de acesso às infraestruturas urbanas que constituem a cidade como "artefato público" (ROLNIK, 2019, p. 14) continuam sendo uma realidade.

Uma forma de fazer frente a esse cenário, é lançar mão do parcelamento, edificação e utilização compulsórios (PEUC), atrelado às sucessivas sanções pelo descumprimento das obrigações (IPTU progressivo no tempo e desapropriação com títulos da dívida pública), todos previstos na Constituição Federal (art. 182, §4ํ, CF). Porém, houve uma baixa adesão dos Municípios na sua utilização: em ampla pesquisa realizada pelo Ministério da Justiça, constatou-se a efetiva aplicação do conjunto de instrumentos em apenas 8 municípios (BRASIL, 2015).

São Paulo, que foi uma das poucas cidades que regulamentou os instrumentos do PEUC e IPTU progressivo e, contando com um estruturado arranjo institucional, deu início ao mais expressivo (em termos quantitativos) processo de notificação de imóveis não edificados, subutilizados ou não utilizados: foram notificados 1.388 imóveis entre 2014 e 2018 e, em 2018, 392 imóveis já estavam sofrendo a incidência de IPTU progressivo no tempo (CAMPOS, 2019). Porém, com a mudança de gestão, a estrutura administrativa montada foi esvaziada com drástica redução das medidas de cumprimento da função social. 
OS MOVIMENTOS SOCIAIS EM SÃO PAULO: ESTRATÉGIAS E AÇÕES PARA AFIRMAÇÃO DO DIREITO À MORADIA NA ÁREA CENTRAL

\subsection{O HISTÓRICO DAS AÇÕES COLETIVAS PELA MORADIA NAS ÁREAS CENTRAIS DE SÃO PAULO}

A demanda por moradia nas áreas centrais de São Paulo deve ser apreciada com um olhar mais amplo sobre a evolução das ações coletivas protagonizadas por movimentos sociais de moradia na cidade e as múltiplas estratégias e ações usadas, sejam elas de natureza insurgente ou institucional.

O processo de urbanização excludente associado a um modelo capitalista periférico, marcado por um processo de industrialização com baixos salários (MARICATO, 1996), ao qual se soma uma insuficiência (ou ausência) de políticas públicas habitacionais para a população de menor renda são os motores de ações coletivas protagonizadas por movimentos de moradia.

A década de 1970 foi marcada por um processo de explosão da periferia, num processo predominante de autoconstrução em parcelamentos irregulares ou ilegais, muitos dos quais caracterizados pela ocupação de áreas ambientais, alagáveis ou de risco. Tal situação leva a uma crescente mobilização de moradores de loteamentos periféricos autoconstruídos ${ }^{8}$, fomenta organização popular e ações coletivas desses moradores na busca de melhorias urbanas por meio da implantação de infraestrutura e serviço nos bairros, bem como defesa do seu direito à terra e à propriedade, no contexto de conflitos possessórios. Tal movimento, segundo James Holston, subverte o conceito de cidadania, que passa a ser entendida de forma insurgente (HOLSTON, 2008). Cresce um discurso sobre o direito a ter direitos em razão da contribuição com a construção da cidade por parte do trabalhador formal que adquiriu um lote e nele construiu sua residência.

Também nesse período surgem os primeiros movimentos organizados em torno da questão das favelas, sua regularização e defesa do direito à terra, sendo emblemático o surgimento do Movimento de Defesa do Favelado (MDF), primeiro movimento de caráter nacional, que passa a atuar ao lado de outros movimentos que tinham caráter regional mais antigos, como a Federação de Favelas do Rio de Janeiro (COMARÚ; BARBOSA, 2019). Esses movimentos passam a contar com aportes de assessorias técnicas, universidades, coletivos e profissionais ligados à administração pública que potencializam a luta urbana (BONDUKI, 2018). Em outras palavras, é do encontro da insurgência com a institucionalidade que a agenda da reforma urbana passa a ter uma estratégia global e rompe com a atuação local.

Rev. Dir. Cid., Rio de Janeiro, Vol. 14, N.01., 2022, p. 138 - 169.

Emanuel Ramos Cavalcanti, Amíria Bezerra Brasil, Ricardo de Sousa Moretti e Julia Azevedo Moretti

DOI: $10.12957 /$ rdc.2022.54363| ISSN 2317-7721 
Nesse sentido, a década de 1980 marca a consolidação (institucionalização) das organizações populares por moradia e a criação de movimentos de âmbito nacional. Num cenário de redemocratização vão se formando os atores do Movimento Nacional da Reforma Urbana (hoje Fórum Nacional da Reforma Urbana) e a mobilização ocorre a partir da perspectiva de participação social no processo constituinte (COMARÚ; BARBOSA, 2019; BONDUKI, 2018). A emenda de iniciativa popular da reforma urbana tratava de uma pauta ampla, mais extensa do que acabou incorporado aos artigos 182 e 183 da Constituição Federal de 1988. Se os temas não eram necessariamente novos e alguns deles já eram discutidos desde o PL 775/83, “[o] diferencial foi a inclusão de muitas das reivindicações dos movimentos de moradia e das entidades técnicas, formuladas durante o processo de redemocratização" (BONDUKI, 2008, p. 103), que traduz a força política advinda de ações coletivas, especialmente de caráter popular protagonizadas por movimentos de moradia.

No plano executivo, pode-se lembrar da pressão e mobilização dos movimentos populares nas gestões municipais da década de 1990, com suas práticas e experimentações inovadoras e, nos últimos anos, na concepção do Minha Casa Minha Vida - Entidades, programa que viabilizou reforma de edifícios em áreas centrais e bem localizadas e tem provido bons exemplos de produção de habitação de qualidade com baixo custo (Figura 3).

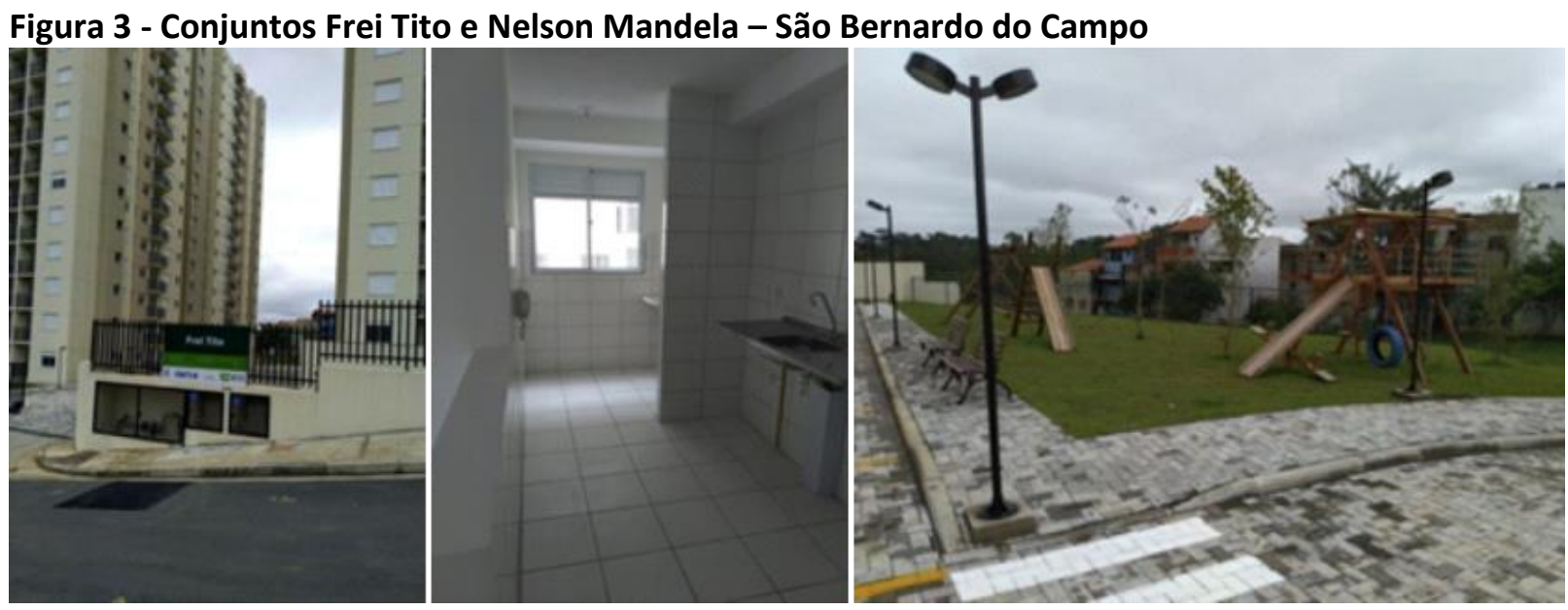

Fonte: Arquivo Pessoal.

A atuação dos movimentos de moradia focada em espaços institucionais foi objeto de críticas, especialmente em razão do distanciamento da base, com diminuição do vigor das estratégias de enfrentamento e organização de base. Ainda que não se defenda o afastamento dos espaços institucionais, a eles deve ser dada "a importância e o peso relativo que têm no conjunto de correlação de forças em jogo e disputa" (COMARÚ; BARBOSA, 2019, p. 39). 
O caráter juridicista e institucional de muitas das conquistas reflete uma "estratégia de pressão/negociação baseada em pequenos avanços sucessivos" (BONDUKI, 2008, p. 109) que aceita as regras do mercado capitalista e aposta na conciliação. No âmbito da justiça ambiental, a discussão se assenta na adoção de mecanismos de "resolução negociada dos conflitos como parte da constituição dos sistemas ditos de 'governança' próprios das dinâmicas extra-estatais das reformas liberalizantes" (ACSELRAD; MELLO; BEZERRA, 2009, p. 96), que sofre fortes críticas por acabar encobrindo conflitos, que permanecem latentes.

Assim, sem recusar a participação em espaços de negociação, inclusive mediante a participação em instâncias institucionais de resolução negociada de conflitos, os movimentos de moradia nunca abandonaram outras estratégias de trabalho de base, que envolve uma ação educativa sobre direitos e deveres, mas também de denúncia e enfrentamento, afinal "quando envolve atores sociais com acentuada desigualdade de poder, a resolução negociada de $\operatorname{conflitos}^{9}$ pode operar como uma tecnologia social de desmobilização social" (ACSELRAD; MELLO; BEZERRA, 2009, p. 101).

O trabalho de base conta com ações de debates, grupos de estudo, teatro, organização de atos e ocupações, medidas que visam a organização e conscientização sobre direitos, deveres, cidadania, enfim, o "desenvolvimento de capacidades e habilidades para convivência em grupos de forma organizada - como observado no caso das ocupações de edifícios abandonados das áreas centrais" (COMARÚ; BARBOSA, 2019, p. 40).

Sobre as ocupações em áreas centrais, insta observar que até o final da década de 1990 elas eram estratégias mais individuais e difusas, ações protagonizadas por indivíduos ou grupos em pequena escala. Considera-se a ocupação do 'Casarão Santos Dumont', no bairro de Campos Elísios, promovida pela Unificação das Lutas dos Cortiços (ULC), como o marco inicial de uma estratégia de ocupações sistemáticas, organizadas e em grande escala que extrapola a desobediência civil ou uma afronta da lei para destacar uma injustiça: usa a lei como justificativa para legitimar a ocupação (imóveis vazios que não cumprem a função social), o que pode ser visto como cidadania transgressiva (EARLE, 2012). Numa linguagem mais lírica, “[o]cupar era uma urgência dos corpos, convertida no mais contundente dos atos políticos, a afrontar a resignação dos serenos. Ocupar, nem que fosse para estar entre muitos, para existir ainda uma vez em coletivo" (FUKS, 2019, p. 105).

O esvaziamento das áreas centrais, em contraste com o aumento populacional em áreas cada vez mais periféricas apesar de ter arrefecido após os anos 2000, ainda é marcante na cidade de São Paulo e a oposição entre o número de imóveis vazios e o déficit habitacional é uma das facetas das contradições urbanas. Na Região Metropolitana de São Paulo (RMSP), por exemplo, a Fundação João 
Pinheiro estima que existam 595.691 domicílios vagos enquanto o déficit habitacional é estimado em 638.763 domicílios (FUNDAÇÃO JOÃO PINHEIRO, 2018). A pressão feita por movimentos de moradia pela ocupação de imóveis vazios é imensa: as ocupações algumas vezes são atos políticos, a exemplo das inúmeras edições do "abril vermelho" ou ocupações relâmpago de instituições governamentais, medidas que visam ampliar a visibilidade do problema (COMARÚ; BARBOSA, 2019). Outras vezes, as ocupações se consolidam como verdadeiras alternativas aos altos custos de aluguel, fator de maior relevância na atual composição do déficit habitacional (FUNDAÇÃO JOÃO PINHEIRO, 2018), a exemplo dos quase 70 imóveis ocupados para fins de moradia na cidade de São Paulo (70\% deles na região central).

Mas a história das ações coletivas cuja pauta é a moradia na região central não se restringe às ocupações por parte dos movimentos sociais. Os cortiços, com sua realidade velada e invisibilidade social, há séculos configuram-se como alternativa habitacional para a população de mais baixa renda que aceita pagar caro e viver em situação de completa precariedade (CARICARI; KOHARA, 2006), mas próximo a pontos de trabalho em regiões centrais. Trata-se de situação de alta vulnerabilidade, que coloca seus moradores numa condição de periferia em termos sociais (EARLE, 2012). Estima-se que existam aproximadamente 80 mil domicílios em cortiços em São Paulo (SÃO PAULO, 2016). Ainda que as primeiras ações remontem à década de 1970, o primeiro grupo organizado do movimento de moradia com foco na habitação do Centro, a Unificação de Lutas de Cortiços (ULC), formou-se apenas em 1991 (CARICARI; KOHARA, 2006).

Se território é poder e a todo poder se opõe um contrapoder (RAFFESTIN, 1993), o histórico de ações coletivas protagonizadas por movimentos de moradia em áreas centrais de São Paulo evidencia as tensões entre poder e contrapoder no espaço urbano, o conflito entre a cidade construída e habitada por pessoas e a cidade do capital, território de disputa do mercado imobiliário, entendendo que conflitos não são disfuncionais: numa sociedade capitalista eles são inerentes e eliminá-los é autoritarismo.

\subsection{AS VISITAS TÉCNICAS PARA QUALIFICAÇÃO DA SEGURANÇA APÓS O INCÊNDIO DO PRÉDIO WILTON PAES DE ALMEIDA E A ABORDAGEM DAS PARCERIAS PÚBLICO-POPULARES}

O incêndio e posterior colapso do prédio Wilton Paes de Almeida ocorrido no dia $1^{\circ}$ de maio de 2018 , teve grande cobertura da mídia e gerou comoção. Era um imóvel de propriedade pública ${ }^{10}$ no centro de São Paulo que fora ocupado por um dos movimentos de moradia que reivindicam 
habitação na área central da cidade. $O$ desastre gerou grande pressão para que fossem tomadas medidas pela Prefeitura, para evitar novas ocorrências.

A Secretaria de Habitação mobilizou técnicos do Corpo de Bombeiros e de diversas áreas da administração municipal que lidam com o licenciamento e segurança de edificações e convidou as lideranças dos movimentos de moradia para um diálogo, que tinha como perspectiva a realização de vistorias nos prédios ocupados, visando a identificação do grau de risco existente. Já de início foi sinalizado que a prefeitura não dispunha de solução habitacional para reassentar as famílias que ocupavam os prédios em risco e que o programa de auxílio aluguel, que naquele momento já tinha mais de 25 mil famílias atendidas, não seria uma solução viável em larga escala.

Os integrantes da assessoria técnica aos movimentos, que estiveram presentes nas primeiras reuniões e acompanharam o processo, procuraram mostrar a necessidade de mudar o caráter destas vistorias. Apontava-se que, por se tratar de prédios antigos, um olhar do grau de risco à luz dos parâmetros normativos da legislação atual levaria à interdição de praticamente todos os prédios ocupados, criando-se um problema social que afetaria milhares de famílias.

Depois de extensos debates, chegou-se à conclusão da realização de visitas, nas quais se buscaria identificar medidas e obras prioritárias para qualificação da segurança dos imóveis, envolvendo tópicos tais quais prevenção de incêndios, problemas estruturais e injúrias físicas, como quedas. Teriam caráter de visita e não de vistoria e seriam acompanhadas por lideranças dos movimentos e por integrantes da assessoria técnica dos movimentos. O foco seria assim a identificação de ações prioritárias para minimizar o problema e não simplesmente a avaliação do grau do problema. Um grupo se formou para levantar e avaliar possíveis fontes de recursos para viabilizar a execução das medidas e obras prioritárias que seriam resultantes de processo de visitas.

As visitas foram realizadas no período de 07 de maio a 14 de junho de 2018. 0 trabalho técnico foi feito em 51 imóveis ocupados, dos quais 46 situados nas subprefeituras da Sé e Mooca. A síntese das informações sobre as visitas foi consolidada em um relatório técnico emitido pela Prefeitura de São Paulo intitulado: "Situação das Ocupações na Cidade de São Paulo" (SÃO PAULO, 2018). Este documento registra uma população estimada de 3.500 famílias e 10.650 pessoas; dentre os 51 imóveis, 44\% estão ocupados há mais de 5 anos, $57 \%$ estão vinculados a algum movimento de moradia e $31 \%$ são de propriedade pública.

Em paralelo ao processo de visitas aos prédios ocupados houve debates com o Ministério Público do Estado de São Paulo, para esclarecer o caráter e objetivo destas visitas. Procurou-se mostrar que a ausência de soluções para a provisão habitacional prevista como direito constitucional, tem 
levado a uma situação em que a população tem que optar entre comer ou pagar aluguel e que a ocupação dos imóveis vem ao encontro da tentativa de fazer cumprir o papel social da propriedade, na medida em que se ocupam prédios que estavam abandonados. Por outro lado, argumentou-se que as ações de reintegração de posse (44 imóveis são objeto de ações judiciais, sendo que para 16 deles havia, em 2018, previsão de reintegração de posse imediata) têm feito apenas mudar o tipo de risco ou o endereço do risco (AUTOR, 2015). Parte dos moradores que estava no prédio Wilton Paes de Almeida, por exemplo, tinham sido alvo de ações de remoção promovidas pela Prefeitura, no bairro dos Campos Elíseos. Por outro lado, a reintegração dos imóveis poderia provocar riscos sociais, talvez até mesmo maiores do que aqueles associados aos incêndios.

Ocorreu, em paralelo também às visitas, uma iniciativa importante, que foi a ajuda voluntária de uma bombeira civil, que era na época estudante de arquitetura e urbanismo e que atuou na formação de brigadas de incêndio em diversos prédios ocupados em que houve interesse neste sentido. A importância desta iniciativa foi demonstrada alguns meses mais tarde, quando ocorreu incêndio em imóvel de 21 andares situado na Avenida Prestes Maia e que felizmente não teve maiores consequências, em decorrência da ação precisa da brigada de incêndio do imóvel. O nível de organização é, inclusive, um dos aspectos analisados no relatório técnico da Prefeitura, que indica que 57\% dos imóveis ocupados estão vinculados a algum tipo de movimento social e que, nesses casos, há maior incidência de componentes de organização, como regimento interno (identificado em $62,7 \%$ dos imóveis ocupados, sendo 52,9\% vinculados a movimentos e 9,8\% sem vínculo com movimento) e algum tipo de manutenção predial (observada em 74,4\% dos imóveis ocupados, sendo 52,9\% dos prédios vinculados a movimentos e os outros $21,6 \%$ sem vínculo com movimento).

Os relatórios resultantes do processo de visita voltada para a qualificação de segurança estão sendo agora base para a tentativa de constituição de uma parceria público-popular (CARVALHO; BEDESCHI, 2019) ${ }^{11}$. A meta é que no caso dos imóveis de propriedade pública, o conjunto de moradores se comprometa e se responsabilize pela implementação gradativa de um conjunto de obras e medidas prioritárias de qualificação de segurança e melhoria das condições de habitabilidade do prédio ao longo do tempo, baseado nos resultados das visitas técnicas, recebendo em troca a concessão do direito de uso do prédio, por um período de 20 ou 30 anos. A propriedade continuaria a ser pública, assegurando-se, assim o atendimento da função social da propriedade pública e a demanda por moradia em local adequado, para a população na faixa de interesse social. 
Por fim, importante destacar que após o desabamento do Edifício Wilton Paes de Almeida houve a abertura de investigações por parte do Ministério Público sobre cobranças e arrecadação de dinheiro dos moradores de ocupações, o que ensejou a prisão, em 2019, de várias lideranças, muitas das quais sequer participavam da ocupação do edifício que desabou. Essa reação, por um lado, mostra a dimensão do processo de criminalização dos movimentos sociais de moradia, mas, por outro, evidencia a importância e a visibilidade que adquiriram estes movimentos.

\section{AS OCUPAÇÕES RECENTES E A ATUAÇÃO DO MOVIMENTO SOCIAL PELA UTILIZAÇÃO DOS VAZIOS URBANOS DA ÁREA CENTRAL DE NATAL}

\subsection{O ESPRAIAMENTO DA OCUPAÇÃO URBANA DE NATAL E O ESVAZIAMENTO DOS BAIRROS CENTRAIS.}

O município de Natal, localizado no litoral do Nordeste do Brasil, possui área de $168 \mathrm{~km}^{2}$, sendo totalmente urbano. Apresentou intenso crescimento territorial durante o século XX, encontrando-se, atualmente, com grande parte do seu território ocupado e um processo avançado de conurbação com outros municípios de sua Região Metropolitana (RMN). Este processo de ocupação, entretanto, não aconteceu de forma contínua e homogênea, tendo sido induzido por processos que caracterizaram social e morfologicamente o território e o marcaram com vazios urbanos diferentes ao longo de sua extensão.

A ocupação inicial do município ocorreu às margens do Rio Potengi, junto ao porto, onde aconteciam as primeiras atividades econômicas, espaço equivalente, hoje, ao bairro da Ribeira que, junto com os bairros Cidade Alta, Rocas e Alecrim conformam hoje o centro histórico de Natal. No início do século XX, a expansão da cidade se deu a partir da delimitação da chamada Cidade Nova área incorporada nos planos urbanísticos posteriores - que conformou o mercado formal de terras e impulsionou o crescimento em sentido leste. A partir da década de 1970 a expansão esteve ligada à construção dos conjuntos habitacionais nas então periferias, inicialmente pelos Institutos de Aposentadorias e Pensões (IAPs) e, depois, pela política do Banco Nacional de Habitação (BNH).

A expansão para o norte, em direção aos limites com Extremoz e São Gonçalo do Amarante, se deu a partir da construção de conjuntos populares pela Companhia de Habitação (COHAB), enquanto para o sul foi impulsionada por empreendimentos do Instituto de Orientação às 
Cooperativas Habitacionais (INOCOOP) voltados para população de mais alta renda, consolidando bairros como Ponta Negra, caracterizado originalmente por sítios e segundas residências (FERREIRA, 2016). A expansão para sul também foi impulsionada por importantes equipamentos como o Centro Administrativo do Governo do Estado e a Universidade Federal do Rio Grande do Norte (UFRN), ambos na década de 1970, o que exigiu a implantação da infraestrutura urbana necessária para este crescimento, como a abertura da rodovia BR-101 (acesso à UFRN e aos conjuntos dos professores e Cidade Satélite), da Avenida Roberto Freire (antiga estrada de Ponta Negra), principal acesso à Ponta Negra e, por fim, da Via Costeira, onde se instalaram parte dos hotéis de suporte à atividade turística (CAVALCANTE, 2019).

Até 1970, o bairro da Ribeira ainda possuía importantes infraestruturas, como as estações rodoviária e ferroviária, o porto (de passageiros e mercadorias), bem como edifícios institucionais (da Prefeitura e do Governo do Estado). Na década de 1980, a transferência da rodoviária para o bairro Cidade da Esperança impactou a atividade comercial e de pequenas hospedagens ligadas a ela, enquanto a retração da atividade ferroviária no Brasil fez com que muitos edifícios perdessem seus usos: a expansão da cidade provocou um processo de esvaziamento desse bairro, o abandono de muitos edifícios e, aos poucos, a Ribeira foi perdendo sua identidade (TINOCO et al., 2008).

A expansão física da cidade também estimulou a expansão do mercado imobiliário formal e o início da verticalização em bairros como Tirol, Petrópolis, Capim Macio e Ponta Negra, com valorização de vazios urbanos deixados ao longo dos eixos de expansão (CAVALCANTE, 2019; FERREIRA, 2016). Nas décadas de 1990 e 2000, a produção imobiliária extrapolou os limites de Natal com a construção de condomínios, principalmente em Parnamirim, consolidando o eixo sudeste e intensificando sua verticalização. Essa expansão foi estimulada pelos investimentos no turismo, tanto em sentido ao litoral sul, quanto em sentido ao litoral norte, o que foi fortalecido em 2014 com a transferência do aeroporto para São Gonçalo do Amarante, com investimentos da Copa do Mundo de Futebol da FIFA (FERREIRA, 2016).

O processo de expansão ao longo do século XX resultou em numerosos vazios urbanos, mas a produção recente de habitação de interesse social (HIS) não ocupou essas áreas, já dotadas de infraestrutura. Ao contrário, centrou-se na produção de novas unidades pelo Programa Minha Casa Minha Vida (PMCMV), destinadas à população de baixa renda (0 a 3 s.m.), mas localizadas nas periferias da cidade (norte e oeste) e nos municípios da RMN. Essa lógica de expansão urbana com a produção de novos empreendimentos se mantém na contramão do que se defende acerca da sustentabilidade urbana. Por outro lado, alguns movimentos sociais reivindicam a ocupação dos vazios 
urbanos centrais e, para tanto, é importante conhecê-los, a partir de um exercício sobre o tema que está sendo feito em Natal.

\subsection{OS VAZIOS URBANOS EM NATAL}

Da parte da Prefeitura, não há um levantamento abrangente e detalhado dos vazios urbanos em Natal. Urge amplo estudo que contemple, especialmente, o conhecimento de processos formadores e transformadores, a definição, a categorização e metodologias de identificação desses espaços. Na prática, os dados produzidos têm sido, notadamente, sobre os terrenos não edificados, mais facilmente identificáveis por imagens orbitais. Além do pouco conhecimento sobre as demais categorias de vazios urbanos (edificações vazias ou subutilizadas, terrenos subutilizados etc.), para que estes dados subsidiassem políticas públicas adequadas, outras informações, para além das configurações morfológicas, como propriedade, situação tributária, tempo de vacância etc. teriam que ser devidamente levantadas. Por fim, o desconhecimento dos vazios urbanos fragiliza, fundamentalmente, a aplicação dos instrumentos urbanísticos (somando-se à omissão do poder público municipal) previstos no Plano Diretor de Natal (PDN), Lei Complementar $n^{\circ}$ 082/07 (vigente e em revisão desde 2017), que não define de forma clara esses espaços, carecendo de detalhamento a partir da Constituição Federal (CF), de 1988, e do Estatuto da Cidade (EC), de 2001.

$\mathrm{Na}$ CF, que estabelece a política urbana nacional (artigos 182 e 183), os vazios urbanos são "[...] solo urbano não edificado, subutilizado ou não utilizado [...]" (BRASIL, 1988), assim como no EC, em seu artigo $5^{\circ}$ (CÂMARA DOS DEPUTADOS, 2001). Neste contexto legislativo, o princípio fundamental é o do cumprimento da função social da cidade e da propriedade a ser operacionalizado por instrumentos como o Parcelamento ou Edificação Compulsórios (PEUC), o Imposto sobre a Propriedade Predial e Territorial Urbana (IPTU) progressivo no tempo e a desapropriação com pagamento mediante de títulos da dívida pública, essenciais no combate à retenção especulativa do solo. Nesta mesma linha de frente, há também o Código Civil (CC), Lei Federal $\mathrm{n}^{\circ}$ 10.406/02, que define, em seus artigos 1.275 e 1.276, a possibilidade da perda da propriedade pelo abandono: “[...] poderá ser arrecadado, como bem vago, e passar, três anos depois, à propriedade do Município ou à do Distrito Federal, se se achar nas respectivas circunscrições" (BRASIL, 2002). A aplicação do CC pode atuar como eficaz instrumento no combate à retenção especulativa do solo e ao arruinamento das edificações, pois a execução da lei no imóvel abandonado pode compreender processo mais célere (aproximadamente 3 anos) se comparado ao do PEUC/IPTU progressivo no tempo/desapropriação 
com pagamento em títulos da dívida pública (podendo levar 15 anos ou mais caso o proprietário não cumpra com as sucessivas notificações).

No PDN, embora associados à aplicação do PEUC e vinculados a ações nas Áreas Especiais de Interesse Social (AEIS), os vazios urbanos permanecem definidos como na CF e no EC, sem aprofundamento em suas definições e sem perspectiva de implementação dos instrumentos urbanos previstos. Atualmente, a revisão do PDN produziu minuta da nova redação do texto da Lei e, a despeito das recomendações feitas por diversos grupos ao longo da revisão ${ }^{12}$, não foram incluídos, por exemplo, conceituação (nem mesmo em glossário) e mapa dos vazios urbanos em Natal (a redação permanece a mesma vigente desde 2007) o que vai comprometer, mais uma vez, a utilização dos instrumentos urbanísticos. Além disso, também não foi inserida a temática das mudanças climáticas, nem sequer a discussão urgente da erosão costeira apontada por diversos estudos (AMARO et al., 2012; BUSMAN et al., 2013), colocando a nova redação do PDN na contramão da normativa nacional, prevista na Lei no 12.187/09 que, como apontando anteriormente, tem sido timidamente incluída nos planos diretores pelo país.

Em âmbito acadêmico local, também não há levantamentos abrangentes, embora estudos de caso por bairro tenham apresentado resultados diversificados sobre os vazios urbanos em Natal. Marinho (2018) e Cavalcante (2019) contribuíram com análise e classificação dos vazios urbanos para os bairros de Lagoa Nova e Ponta Negra, respectivamente, identificando terrenos vazios e sem uso como significativas áreas de especulação imobiliária e de empreendimentos para classes média e alta. Silva (2019), por sua vez, analisou o potencial de transformação dos vazios urbanos no bairro Mãe Luiza, zona costeira e importante AEIS da cidade.

Atualmente em execução, o projeto de pesquisa "Omitido para avaliação às cegas" ${ }^{13}$, vem contribuindo para um levantamento abrangente dos vazios urbanos na cidade, a partir de fundamentação teórica e rigor metodológico na categorização destes espaços e na elaboração de alguns estudos de caso, como, por exemplo, para os bairros de Capim Macio, Ribeira e Rocas. O primeiro destes bairros, é área de expansão recente, com considerável oferta de empreendimentos residenciais (condomínios verticais) de médio e alto padrões; os dois últimos, compreendem a área central histórica de Natal, onde é possível observar, na última década, significativa pressão do mercado imobiliário (verticalização), atraído pelo notável número de terrenos e edificações vazias (não utilizadas ou subutilizadas), sejam como resultado do esvaziamento constante das atividades industriais (ferroviárias e portuárias inclusas), sejam ruínas de antigas edificações (muitas de 
significativo valor histórico). Somam-se a este cenário, a presença de algumas áreas/edificações com ocupações para fins de habitação social, assunto detalhado a seguir.

\subsection{OS MOVIMENTOS SOCIAIS E OS ESFORÇOS PARA A PERMANÊNCIA NA ÁREA CENTRAL DE NATAL}

Em 2010, o déficit habitacional em Natal contabilizava $22.185 \mathrm{UHs}^{14}$ e, durante esta década, a produção de HIS contabilizou um total 2.864 novas UHs pelo PMCMV até 2015. Além do desencontro dos números, não houve aproveitamento dos edifícios vazios presentes nos bairros do núcleo original da cidade, já providos de infraestrutura. Recentemente, diante da crescente necessidade habitacional e das discussões dos impactos de se deslocar na cidade, movimentos sociais - em especial, o Movimento Nacional da População em Situação de Rua (MNPR) e o Movimento de Luta nos Bairros, Vilas e Favelas (MLB) - começaram a pressionar a Prefeitura por moradia e assistência social em áreas acessíveis e com infraestrutura, questionando sobre os vazios urbanos dos bairros centrais, em especial da Ribeira.

Em Natal, não há um número exato da população em situação de rua ${ }^{15}$, mas de acordo com os dados da Secretaria Municipal de Trabalho e Assistência Social (SEMTAS) há mais de 1.000 cadastros sociais (NATAL, 2018). Os bairros de maior concentração das pessoas em situação de rua são os centrais - Alecrim, Cidade Alta e Ribeira - e alguns na Região Norte (NATAL, 2018). Atualmente, há poucos equipamentos de suporte: três albergues na Cidade Alta que atendem cerca de 60 pessoas e um Centro POP ${ }^{16}$, que foi fechado e reaberto recentemente, no bairro Barro Vermelho.

Em 2018, o Conselho Municipal de Habitação de Interesse Social (CONHABINS) recebeu uma demanda do MNPR e sistematizou um documento sobre a situação dessas pessoas e encaminhou suas solicitações para o Ministério Público do Rio Grande do Norte (MP/RN) com reivindicação especialmente de utilização de edificações vazias nos bairros centrais, onde já existe infraestrutura disponível e já se concentra parte dessa população. A solicitação encaminhada ao MP/RN pede à Secretaria Municipal de Tributação (SEMUT) que sejam identificados imóveis vazios - terrenos e edifícios - e em dívida com o Fisco para que sejam aplicados os instrumentos adequados e que possam ser transformados em HIS ou equipamentos. Solicita também que dois dos imóveis do Patrimônio da União, no bairro da Ribeira, atualmente vagos, sejam cedidos ao Município de Natal e destinados a equipamentos de atendimento ao MNPR (NATAL, 2018).

Rev. Dir. Cid., Rio de Janeiro, Vol. 14, N.01., 2022, p. 138 - 169.

Emanuel Ramos Cavalcanti, Amíria Bezerra Brasil, Ricardo de Sousa Moretti e Julia Azevedo Moretti 
A primeira edificação está situada na Esplanada Silva Jardim, $n^{\circ} 76$, esquina com Rua Frei Miguelino (Figura 4). A Prefeitura não aceitou a cessão proposta pelo MP/RN, alegando não ter recursos para a adaptação e manutenção do edifício e serviços adequados e, em Ofício do dia 04 de maio de 2020, a Secretaria do Patrimônio da União (SPU) comunicou ao MP que o edifício "foi ofertado à Associação Centro Católico de Evangelização Reviver Pela Misericórdia" (BRASIL, 2020), que já apresentou a documentação necessária. O outro imóvel é um conjunto de galpões da extinta Rede Ferroviária Federal S/A (RFFSA), situados na Rua Almino Afonso, $n^{\circ} 21$ (Figura 4). Esses galpões foram aceitos pela Prefeitura, mas segundo o Ofício supracitado, "foi ofertado para o Município do Natal/RN, para que seja utilizado como estacionamento para os servidores públicos" (BRASIL, 2020).

Figura 4 - Edifício do SPU (esquerda) e Galpões da RFFSA (direita) solicitados pelo MNPR para construção de equipamentos e HIS de apoio à população em situação de rua
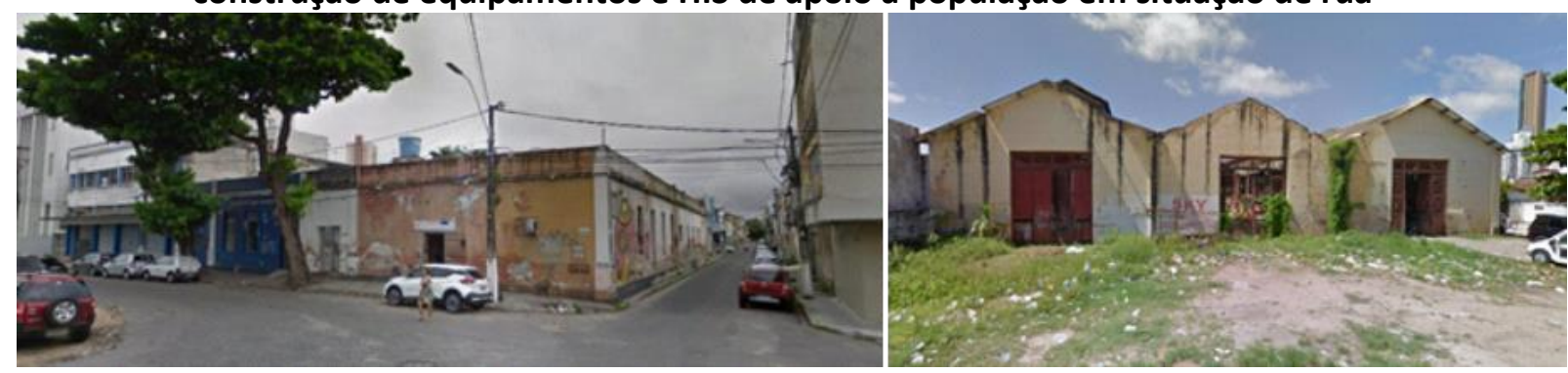

Fonte: Google Street View (11 de maio de 2020).

Já o MLB, que tem histórico de participação em órgãos colegiados de política urbana, atuou a partir de uma ocupação em 2015 de um terreno também da RFFSA, vizinho ao atual Instituto Federal do Rio Grande do Norte (IFRN) (Figura 5). A ocupação intitulada "Padre Sabino" tinha mais de 100 famílias e seu objetivo era pressionar a Prefeitura pelo diálogo sobre as condições de moradia da população.

A Prefeitura negociou com as famílias a desocupação do terreno, que foi incorporado ao imóvel do IFRN. Do total, 110 delas foram incluídas no PMCMV e atendidas no Conjunto Village de Prata - no longínquo bairro Planalto (a cerca de $11 \mathrm{~km}$ de distância). Aquelas famílias que não foram incluídas fizeram uma nova ocupação, dessa vez em um antigo albergue desocupado da Prefeitura, na Rua Câmara Cascudo também na Ribeira (Figura 5). Essa ocupação, assim como a outra, tem o objetivo de pressionar o poder público municipal para dialogar sobre soluções de moradia para as demais famílias do movimento, visto que o atendimento anterior não foi suficiente. 
Figura 5 - Terreno ocupado pelo MLB (esquerda) e Edifício do antigo Albergue da Prefeitura pelo MLB

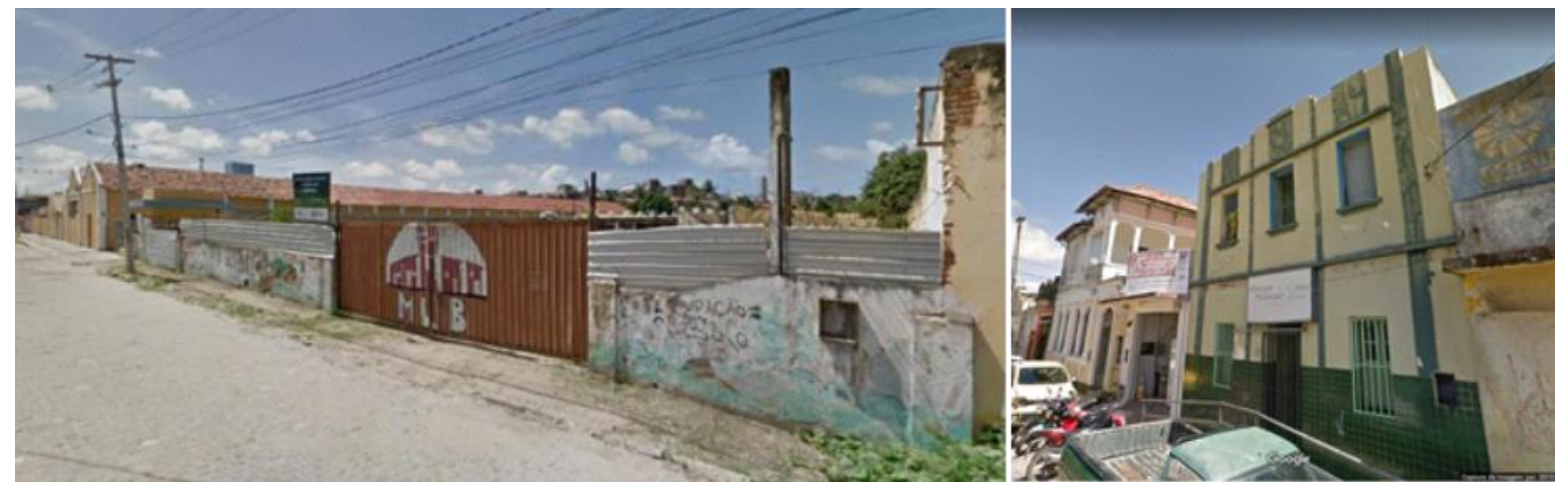

Fonte: Google Street View (11 de maio de 2020).

Denominada de "Pedro Melo", essa ocupação possui 21 famílias, 39 pessoas ao todo, tendo se estabelecido no dia 22 de dezembro de 2018. Cada família, em geral, ocupa um cômodo e todos dividem as áreas molhadas (um banheiro e uma lavanderia). As cozinhas são improvisadas dentro dos quartos. Toda a adaptação do edifício foi feita pelo movimento ${ }^{17}$, incluindo ligações de água e energia e soluções de esgotamento sanitário, o que demandaria algumas medidas de qualificação de segurança. Estima-se que com medidas adequadas o edifício poderia abrigar cerca de 20 famílias, mas paira o risco de que se concretize a ação de reintegração de posse do imóvel, atualmente em tramitação.

As discussões em curso, iluminadas pelas ações desses dois movimentos, mostram a necessidade e a possibilidade de utilização dos vazios urbanos dos bairros centrais da cidade, em especial, a Ribeira, que possui muitos edifícios e alguns terrenos vazios, com boas condições de infraestrutura e que se situam próximo às principais áreas de oferta de emprego. Entretanto, ainda se opta pelo modelo de construção de novas unidades nas áreas periféricas, intensificando a urbanização dispersa.

\section{CONSIDERAÇÕES FINAIS: PARALELOS ENTRE A SITUAÇÃO DE SÃO PAULO E NATAL}

São Paulo e Natal são duas cidades de porte muito distinto, de estruturas culturais, sociais e econômicas muito diferentes, mas que apresentam vários pontos de convergência quando se trata de analisar sua dinâmica de ocupação urbana expansiva, periférica, desigual. Há convergências também na tentativa insurgente (ou transgressiva) dos movimentos sociais de enfrentar o eixo hegemônico das políticas urbanas, dando visibilidade às desigualdades, ao problema dos imóveis ociosos nos centros urbanos. 
Em que pese a existência de um importante marco normativo que possa dar base à utilização de imóveis ociosos num viés inclusivo, articulando moradia, justiça climática e direito à cidade, as políticas urbanas não foram plenamente capazes de abordar essa agenda afinada com a ideia de reforma urbana. Políticas de provisão habitacional como Minha Casa Minha Vida continuaram a produzir conjuntos periféricos, em locais com baixa oferta de trabalho e serviços públicos, reforçando o movimento pendular moradia trabalho e impulsionando, cada vez mais, a expansão urbana, o que traz mais impacto na mobilidade (e, consequentemente, emissão de GEE) e demanda mais conversão de áreas verdes e ampliação da já frágil infraestrutura urbana (em prejuízo às necessárias medidas de adaptação). A regulamentação e efetiva implantação de políticas para fazer cumprir a função social da propriedade e da cidade, utilizando, por exemplo, o PEUC, seguem a passos lentos e sofrem constantes ataques, seja no plano legislativo (vide discussão da PEC $80 / 2019^{18}$ ) ou no desmonte deliberado de políticas em curso, a exemplo do que ocorreu na cidade de São Paulo. Os impasses jurídicos, urbanísticos e financeiros para a qualificação da segurança de prédios ocupados, evitando-se a remoção dos moradores é questão premente ainda não equacionada. A resistência dos movimentos, no entanto, continua tentando dar visibilidade ao problema da quantidade de imóveis centrais ociosos e incidir em políticas públicas, construindo alternativas para uso desses imóveis numa prática de cidadania transgressiva (EARLE, 2012), aquela que toma a lei como partida para a interlocução com o Estado e suas políticas públicas. Nesse sentido, o movimento popular empreende esforços, nas duas cidades, pela afirmação do direito constitucional à moradia e tem adotado estratégias de ação direta por meio da utilização dos imóveis vazios nas áreas centrais, através da ocupação destes imóveis, seguindo os preceitos da função social da propriedade presente na Constituição, no Estatuto da Cidade e nos Planos Diretores de cada uma dessas cidades.

A pandemia do novo coronavírus (Sars-CoV-2) traz novos cenários, novos desafios, aumentando a complexidade dessa articulação entre justiça climática, moradia central e direito à cidade, não apenas em São Paulo e Natal. Os grandes deslocamentos a serem vencidos em transporte coletivo expõem a população mais vulnerável de forma desproporcional e o uso intensivo do automóvel tem grande impacto nas emissões de GEE. Políticas urbanas que permitam um padrão de uso e ocupação do solo que gere menos deslocamentos serão fundamentais e, mais que nunca, buscar formas para utilizar os imóveis das áreas onde estão os empregos é estratégico. As infraestruturas urbanas, já consideradas aspectos vulneráveis das cidades brasileiras às mudanças climáticas, precisam ser melhoradas de forma a garantir universalização de serviços como o saneamento que tem se mostrado tão essencial no combate à Covid-19. Assegurar moradia em área central, colocando em 
uso os imóveis ociosos além de assegurar o necessário distanciamento social, impossível em áreas altamente adensadas, permite o acesso a uma infraestrutura já existente. No auge da crise discutiu-se o uso de quartos de hotéis ${ }^{19}$ e a questão dos imóveis vazios ou subutilizados foi bastante dificultada pela necessidade de adaptação de vários imóveis, bem como por discussões acerca da articulação de medidas como o PEUC e abandono com as medidas de requisição, autorizadas pela Lei no 13.979/2020, que dispõe sobre as medidas para enfrentamento da emergência de saúde pública decorrente do novo coronavírus, condicionando-as à posterior indenização. No período imediatamente após a crise aguda será necessário garantir a continuidade de medidas como aquelas que ampliaram acesso à água e aumentaram a oferta de locais de moradia adequada em áreas centrais.

Os movimentos sociais com suas práticas apontam caminhos para o enfrentamento das mudanças climáticas de forma inclusiva. O que fazer para que sejam escutados, é a questão que se coloca.

\section{Notas}

1. A legislação pátria (Lei 13.465/2017 no art. 11, VIII; CPC nos arts. 554, §§1ํe 2ํ, 590, parágrafo único) adota o termo "ocupante" como vocábulo operacional, sendo essa expressão autêntica para designar aquele "que mantém poder de fato sobre lote ou fração ideal de terras públicas ou privadas em núcleos urbanos informais". (FERREIRA, 2019, p. 104). Assim, as ações coletivas promovidas por movimentos sociais de moradia que adotam estratégias de ocupação de prédios ociosos como forma de reivindicar a afirmação do direito constitucional à moradia são entendidas nesse contexto normativo como ocupações, devendo-se afastar a utilização de termos depreciativos como "invasão".

2. São exemplos de impactos das mudanças climáticas nas populações vivendo em núcleos urbanos informais e ambulantes: mortalidade e aumento de doenças decorrentes de oscilações térmicas (ondas de calor e dias mais frios), agravados pela densidade das ocupações, baixa qualidade térmica dos materiais construtivos, exposição dos trabalhadores às intempéries e aumento de vetores de doenças (como mosquitos). Também danos à vida, ao patrimônio e infraestrutura, em razão de deslizamentos, alagamentos mais frequentes (alterações de regime pluvial, eventos extremos recorrentes e aumento do nível do mar), situações que podem ainda comprometer as fontes de abastecimento de água potável (DODMAN; ARCHER; SATTERHWAITE, 2019).

3. O Relatório Especial sobre Cidades e Mudanças Climáticas dá grande destaque às infraestruturas urbanas como aspectos vulneráveis das cidades brasileiras às mudanças climáticas (PBMC, 2016).

4. O Relatório Especial sobre Cidades e Mudanças Climáticas (PBMC, 2016) é emblemático nesse sentido: reconhece que a mudança climática acentua riscos existentes e decorrentes de um padrão de desenvolvimento urbano com déficits em infraestrutura e menciona, para cada setor de infraestrutura, fragilidades associadas à falta de acesso. Porém as alternativas de mitigação e adaptação apresentadas não tem uma abordagem inclusiva e as desigualdades passam longe do vocabulário e das ações propostas no relatório.

5. Tais conceitos estão definidos na Lei no 12.187/09 e Decreto no 9.578/18 que tratam da Política Nacional sobre Mudança do Clima, sendo mitigação "mudanças e substituições tecnológicas que reduzam o uso de recursos e as emissões por unidade de produção, bem como a implementação de medidas que reduzam as emissões de gases de efeito estufa e aumentem os sumidouros" (art. 2으, VII, Lei no 12.187/09) e adaptação "iniciativas e medidas para reduzir a vulnerabilidade dos sistemas naturais e humanos frente aos efeitos atuais e esperados da mudança do clima" (art. 2으, I, Lei no 12.187/09).

6. O inventário ainda não está disponível ao público, mas foi noticiado no site da Prefeitura Municipal de São Paulo (SÃO PAULO, 2019). 
7. Na Região Metropolitana de São Paulo as viagens a pé representam 31,8\% das viagens (METRÔ, 2019).

8. A autoconstrução periférica serviu ao capital, reduzindo os custos de reprodução da força de trabalho e permitindo a redução de salários e, dessa forma, a própria omissão do Estado no controle do uso do solo em grande parte do território das cidades pode ser considerada uma ausência intencional adequada aos interesses na expansão industrial e conivente com o desejo da elite de manter a segregação na cidade, um processo que ficou conhecido como 'espoliação urbana', na consagrada expressão cunhada por Lúcio Kowarick (EARLE, 2012). 9. Em relação inclusive a agenda de direitos, os referidos autores tratam as práticas de formação de consenso e resolução negociada como formas de "dissolver a discussão sobre direitos e reintroduzir a variável 'força' em conflitos particulares: o encaminhamento do conflito não se dá pela discussão sobre aquilo que é justo ou injusto, mas pela maior ou menor capacidade dos agentes de barganharem seus interesses" (ACSELRAD; MELLO; BEZERRA, 2009, p. 101). Ainda assim, são relevantes os trabalhos vinculados à noção de conflito cooperativo, a qual pode ser vista como uma saída possível entre a tensão que se estabelece entre a ideia habermasiana de consenso vis-à-vis a ideia foucaultiana de conflito. O conflito cooperativo reconhece a coexistência das duas dimensões, uma vez que os padrões de cooperação são úteis para organizações sociais interdependentes que sustentam um processo de produção que, no entanto, gera conflitos por divisões (SEN, 1990). Amartya Sen, com base no conceito de Nash de problemas de negociação, entende o conflito cooperativo como "relações qualitativas na forma de respostas direcionais do resultado a certas variáveis determinantes da base de informações" (SEN, 1990, p. 125 - tradução nossa).

10. O imóvel pertencia à União Federal e estava vazio desde o início dos anos 2000 quando deixou de ser a sede da Polícia Federal. Desde então, apenas chegou a ser ocupado por uma agência do Instituto Nacional do Seguro Social (INSS) e as condições de degradação e abandono acabaram frustrando as tentativas de dar destinação ao prédio. Atualmente, foi firmado um acordo entre o Governo Federal e a Prefeitura de São Paulo para a construção de moradia popular no terreno que antes abrigava o edifício.

11. Com outra abordagem, mas também reforçando iniciativas de caráter local, tramita na Câmara dos Deputados um PL sobre Parceria-Público Privada Popular. O PL 4517/19 permite o repasse de recursos públicos para moradores de uma quadra ou conjunto realizarem pequenas obras de melhorias urbanas, como calçamento, reforma de equipamentos públicos, criação de espaços de lazer ou áreas verdes. É possível a cessão de áreas públicas para a realização das obras e/ou serviços, que são realizados tendo como contrapartida possível a redução de impostos incidentes nos imóveis dos requerentes. O PL prevê ainda a parcerias mais ampliadas, por meio de Operações Urbanas Consorciadas (OUCs), sem especificar detalhes da operacionalização. Há questões polêmicas sobre a finalidade da destinação de recursos e de bens públicos (como estacionamento e segurança comunitária), inclusive porque implicariam em restrição de acesso e cobrança, sem referência a questões licitatórias. De qualquer forma, as condições para repasse direto à população tornam a aplicação bastante limitada, pois o instrumento só poderia ser usado em municípios com até 200 mil habitantes e para obras de até $R \$ 150$ mil.

12. Os autores deste artigo (professores Autor e Autor) participaram do processo de revisão do Plano como membros do projeto de extensão "Omitido para avaliação às cegas", propondo, dentre outras alterações/incorporações, definições e classificações para os vazios urbanos.

13. Coordenado pelos autores deste artigo, professores Autor e Autor, desenvolvido no "Omitido para avaliação às cegas" da "Omitido para avaliação às cegas".

14. Déficit Habitacional Municipal no Brasil (2010/FJP-MCIDADES, 2013 apud FERREIRA, 2016).

15. Compreendemos as pessoas em situação de rua como "um grupo populacional heterogêneo, mas que possui em comum a pobreza extrema, os vínculos familiares interrompidos ou fragilizados e a inexistência de moradia convencional regular" (SILVA, 2006, p.22), ou seja, o estrato mais vulnerável da sociedade (NATAL/ SEHARPE, 2018).

16. “Centro POP na Tipificação Nacional é classificado como serviço especializado para Pessoas em Situação de Rua. [...] tem como finalidade desenvolver sociabilidades, analisar as demandas dos usuários, promover orientação individual e coletiva e encaminhar os usuários a demais serviços socioassistenciais. O Centro deve oferecer espaços de guarda de pertences, higiene pessoal e alimentação, bem como prover documentação civil e endereço institucional" (NATAL/ SEHARPE, 2018).

17. As observações acerca da adaptação do edifício para moradia temporária das famílias do movimento foram feitas em visita à ocupação em 2019.

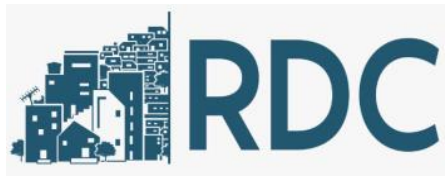

Rev. Dir. Cid., Rio de Janeiro, Vol. 14, N.01., 2022, p. 138 - 169.

Emanuel Ramos Cavalcanti, Amíria Bezerra Brasil, Ricardo de Sousa Moretti e Julia Azevedo Moretti

DOI: $10.12957 /$ rdc.2022.54363| ISSN 2317-7721 
18. A PEC no 80/2019, de autoria do Senador Flávio Bolsonaro, altera o art. 182 da Constituição dando novos contornos ao conceito de função social retirando do Plano Diretor a plena atribuição de significado ao princípio de acordo com os conflitos, realidade e necessidades locais, bem como restringindo o uso dos instrumentos para fazer cumprir o uso compulsório de imóveis ociosos, acabando com a desapropriação com títulos da dívida pública (indenização sempre pelo valor de mercado) e passando a exigir autorização legislativa ou ordem judicial para decretação do descumprimento da função social e utilização do parcelamento, edificação e utilização compulsórios (PEUC), atrelado às sucessivas sanções pelo descumprimento das obrigações (IPTU progressivo no tempo e desapropriação com títulos da dívida pública).

19. Em cidades como Londres e Paris, quartos de hotéis passaram a ser oferecidos para famílias de sem-teto. No Brasil, um forte movimento pressionou os governos a demandarem o uso das vagas ociosas da rede hoteleira para assegurar o isolamento social de famílias vulneráveis. As medidas frutíferas foram basicamente resultado de acordos voluntários, mas em muitos casos houve restrições ao uso dos hotéis para moradores de rua.

\section{REFERÊNCIAS BIBLIOGRÁFICAS}

ACSELRAD, Henri; MELLO, Cecília Campelo do Amaral; BEZERRA, Gustavo das Neves. 0 que é justiça ambiental. 1. ed. Rio de Janeiro: Garamond, 2009.

ALFONSIN, Betânia de Morais; SALTZ, Alexandre; FERNANDEZ, Daniel; VIVAN FILHO, Gerson Tadeu Astolfi; FACCENDA, Guilherme; MULLER, Renata. Das Ruas de Paris a Quito: o Direito à Cidade na Nova Agenda Urbana - Habitat III. Revista de Direito da Cidade, Rio de Janeiro, v. 09, n. 3, p. 1.214$1.245,2017$.

AMARO, Venerando Eustáquio (Coord.); SCUDELARI, A. C.; NEVES, C. F.; TABOSA, W. F.; LIMA Z. M.; SANTOS JR., O. F.; FERREIRA, A. T. S.; SANTOS, A. L. S.; BUSMAN, D. V. Laudo Pericial Item B - Obras Emergenciais de Contenção e Reparação dos Equipamentos Públicos e de Segurança dos Frequentadores da Praia de Ponta Negra, Natal - RN. Natal: UFRN - Centro de Ciências Exatas e da Terra (Departamento de Geologia), 2012.

APOLLARO, Camila; ALVIM, Angélica Tanus Benatti. Planejamento urbano para a adaptação de cidades frente à mudança climática - Uma análise sobre o Plano Diretor Estratégico do Município de São Paulo. Thésis, Rio de Janeiro, v. 2, n. 4, p. 118-137, nov./ dez. 2017.

BUSMAN, D.V.; AMARO, V.E.; PRUDÊNCIO, M.C.; LIMA, F.G.F.; MATOS, M.F.A.; MOURA, J.E. Shoreline changes from 1986 to 2010 on Ponta Negra beach, Natal / RN, Northeast Brazil. SCACR International Short Course, Conference on Applied Coastal Research. Lisboa, Portugal: SCACR International Short Course, 2013.

BONDUKI, Nabil. Dos movimentos sociais e da luta pela reforma urbana na Constituinte ao Estatuto da Cidade (1981-2001). In: BONDUKI, Nabil (org.). A luta pela reforma urbana no Brasil: do Seminário de Habitação e Reforma Urbana ao Plano Diretor de São Paulo. São Paulo: Instituto Casa da Cidade, 2018. p. 81-136.

BRASIL. MINISTÉRIO DA JUSTIÇA. Parcelamento, edificação ou utilização compulsórios e IPTU progressivo no tempo: regulação e aplicação. Brasília: Ministério da Justiça, Secretaria de Assuntos 
Legislativos (SAL), 2015. Disponível em:

http://pensando.mj.gov.br/wpcontent/uploads/2015/11/PoD_56_web1.pdf. Acesso em: 24 jan. 2020.

BRASIL. Ofício SEI N 105505/2020/ME. Natal: Superintendência do Patrimônio da União no Rio Grande do Norte (SPU-RN), 2020.

CALGARO, Cleide; RECH, Moisés João. Justiça Ambiental, Direitos Humanos e Meio Ambiente: uma relação em construção. Revista de Direito e Sustentabilidade, Florianópolis, v. 3, n. 2, p. 1-16, jul./dez. 2017.

CAMPOS, Gustavo Soares Pires de. Função Social da Propriedade na escala da Metrópole: construção de uma política fundiária e atuação do Departamento de Controle da Função Social da Propriedade na Cidade de São Paulo (2013-2016). 2019. Dissertação (Mestrado em Arquitetura e Urbanismo) - Faculdade de Arquitetura e Urbanismo, Universidade de São Paulo, São Paulo, 2019.

CARICARI, Ana Maria; KOHARA, Luiz Tokuzi (orgs.). Cortiços de São Paulo: soluções viáveis para habitação social no centro da cidade e legislação de proteção à moradia. São Paulo: Mídia Alternativa: Centro Gaspar Garcia de Direitos Humanos; Salvador, BA: CESE, 2006.

CARVALHO, Celso Santos; BEDESCHI, Luciana. Parceria Público Popular: uma proposta social contra a especulação imobiliária. Carta Capital, São Paulo, ago. 2019. Seção Blog BrCidades. Disponível em: https://www.cartacapital.com.br/blogs/br-cidades/parceria-publico-popular-uma-proposta-socialcontra-a-especulacao-imobiliaria/. Acesso em: 25 mai. 2020.

CAVALCANTE, Saulo Matheus de Oliveira Lima. 2019. Especulação sol e mar: os vazios urbanos de Ponta Negra. Trabalho Final de Graduação (Arquitetura e Urbanismo) - Universidade Federal do Rio Grande do Norte, Natal, 2019.

COMARÚ, Francisco de Assis.; BARBOSA, Benedito. Movimentos Sociais e habitação. Salvador: UFBA, Escola de Administração; Superintendência de Educação à Distância, 2019.

DODMAN, David; ARCHER Diane; SATTERTHWAITE, David. Editorial: Responding to climate change in contexts of urban poverty and informality. Environment and Urbanization, v. 31, n.1, p. 3-12, abr. 2019. Disponível em: https://journals.sagepub.com/doi/pdf/10.1177/0956247819830004. Acesso em: 25 mai. 2020.

EARLE, Lucy. From Insurgent to Transgressive Citizenship: Housing, Social Movements and the Politics of Rights in São Paulo. Journal of Latin American Studies, v. 44, n. 1, p. 97-126, 2012.

ESPÍNDOLA, Isabela Battistello; RIBEIRO, Wagner Costa. Cidades e mudanças climáticas: desafios para os planos diretores municipais brasileiros. Cadernos Metrópoles, v. 22, n.48, p. 365-395, mai. /ago. 2020.

FERREIRA, Allan Ramalho. Os limites do reconhecimento do ocupante como sujeito da política fundiária: uma reflexão sobre os corpos que não importam. In: CHIARELLO, Felipe; PIRES, Lilian Regina Gabriel Moreira (org.). Novos paradigmas da regularização fundiária urbana. São Paulo: Almedina, 2019. 
FERREIRA, Glenda Dantas. Produção habitacional, agentes e território: uma análise do PMCMV na RMNatal (2009-2014). 2016. Tese (Doutorado em Arquitetura e Urbanismo) - Universidade Federal do Rio Grande do Norte, Natal, 2016.

FUKS, Julián. A ocupação. São Paulo: Companhia das Letras, 2019.

HOLSTON, James. Insurgent Citizenship: disjunctions of democracy and modernity in Brazil. Princeton e Oxford: Princeton University Press, 2008.

IPCC. Climate Change 2014: impacts, adaptation, and vulnerability: Part A: global and sectoral aspects. Cambridge, UK: Cambridge University Press, 2014. p. 1-32. Disponível em: https://www.ipcc.ch/site/assets/uploads/2018/02/WGIIAR5-PartA_FINAL.pdf. Acesso em: 26 mai. 2020.

FUNDAÇÃO JOÃO PINHEIRO. Déficit Habitacional no Brasil 2015. Belo Horizonte: FJP, 2018.

MARICATO, Ermínia. Metrópole na periferia do capitalismo: ilegalidade, desigualdade e violência. São Paulo: Hucitec, 1996.

MARQUES, Eduardo; REQUENA, Carolina. O centro voltou a crescer? Trajetórias demográficas diversas e heterogeneidade na São Paulo dos anos 2000. In: Novos Estudos, no 95, p. 17-36, março 2013.

MARTINS, Rafael D'Almeida.; FERREIRA, Leila da Costa. Uma revisão crítica sobre cidades e mudança climática: vinho velho em garra nova ou um novo paradigma para a governança local? Revista da Administração Pública (RAP), v. 45, n. 3, p. 611-641, mai. /jun. 2011.

METRÔ (Companhia do Metropolitano de São Paulo). Pesquisa Origem Destino 2017: Versão 4, 24/07/2019. Disponível

em:http://www.metro.sp.gov.br/pesquisaod/arquivos/Ebook\%20Pesquisa\%200D\%202017_final_24 0719_versao_4.pdf. Acesso em: 20 mai. 2020.

AUTOR, 2015. Omitido para avaliação às cegas.

NATAL. EU NÃO TENHO ONDE MORAR. Relatório sobre a população em situação de rua na cidade do Natal: encaminhamentos preliminares em busca da elaboração de políticas habitacionais. Natal: Secretaria Municipal de Habitação, Regularização Fundiária e Projetos Estruturantes, 2018.

REDE NOSSA SÃO PAULO. Mapa da Desigualdade 2019. São Paulo: Rede Nossa São Paulo, 2019. Disponível em: https://www.nossasaopaulo.org.br/2019/11/05/mapa-da-desigualdade-2019-elancado-em-sao-paulo/. Acesso em: 26 mai. 2020.

PBMC. Mudanças Climáticas e Cidades. Relatório Especial do Painel Brasileiro de Mudanças Climáticas. Rio de Janeiro: PBMC, COPPE-UFRJ, 2016. Disponível em:http://www.pbmc.coppe.ufrj.br/documentos/Relatorio_UM_v10-2017-1.pdf. Acesso em: 26 mai. 2020.

RAFFESTIN, Claude. Por uma Geografia do Poder. São Paulo: Editora Ática, 1993.

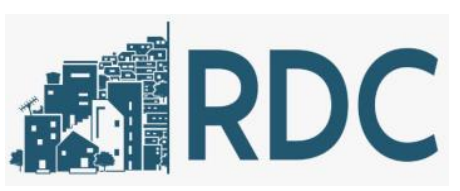

Rev. Dir. Cid., Rio de Janeiro, Vol. 14, N.01., 2022, p. 138 - 169.

Emanuel Ramos Cavalcanti, Amíria Bezerra Brasil, Ricardo de Sousa 
RAMMÊ, Rogério Santos. A política da justiça climática: conjugando riscos, vulnerabilidades e injustiças decorrentes das mudanças climáticas. Revista de Direito Ambiental, v. 17, n. 65, p. 367389, jan. /mar. 2012.

ROLNIK, Raquel. Guerra dos Lugares: a colonização da terra e da moradia na era das finanças. 2aㅡ ed. São Paulo: Boitempo, 2019.

SÃO PAULO. Ambiente: São Paulo apresenta Inventário sobre Emissões de Gases de Efeito Estufa. Portal de Notícias, São Paulo, ago. 2019. Disponível em: http://www.capital.sp.gov.br/noticia/ambiente-sao-paulo-apresenta-inventario-sobre-emissoes-degases-de-efeito-estufa. Acesso em: 24 mai. 2020.

. Situação das Ocupações na Cidade de São Paulo (Relatório). São Paulo, 2018.

Disponível em:

Plano Municipal de Habitação de São Paulo - Projeto de Lei no 619/16. São Paulo, 2016.

https://gestaourbana.prefeitura.sp.gov.br/wpcontent/uploads/2014/08/20161221_PMH_PL_bxa.pdf ._Acesso em: 26 mai. 2020.

SEN, Amartya. Gender and cooperative conflicts. In: Tinker, I. (org). Persistent inequalities: women and world development. New York; Oxford: Oxford University Press, 1990.

SILVA, Maria Lucia Lopes da. Mudanças recentes no mundo do trabalho e o fenômeno população em situação de rua no Brasil 1995-2005. 2006. Dissertação (Mestrado em Política Social) Universidade de Brasília, Brasília, 2006.

SOUZA, Luciana Correia Gaspar; SOTTO, Débora. A lei de mudanças climáticas da cidade de São Paulo: aspectos ambientais e urbanísticos. Revista Direito Ambiental e Sociedade, Caxias do Sul, v. 2, n. 1, p. 318-346, 2012.

TAVOLARI, Bianca. Direito à cidade: uma trajetória conceitual. Novos Estudos, ed. 104, v. 35, n. 1, p. 93-108, mar. 2016,

TINOCO, Marcelo Bezerra de Melo; BENTES SOBRINHA, Maria Dulce Picanço; TRIGUEIRO, Edja Bezerra Faria (Orgs.). Plano de reabilitação de áreas urbanas centrais - PRAC/Ribeira. Natal: EDUFRN, 2008.

WILLIAMS, David Samuel; COSTA, Maria Máñez; SUTHERLAND, Catherine; CELLIERS, Louis; SCHEFFRAN, Jürgen. Vulnerability of informal settlements in the context of rapid urbanization and climate change. Environment and Urbanization, v. 31, n. 1, p. 157-176, abr. 2019. Disponível em: https://journals.sagepub.com/doi/full/10.1177/0956247818819694. Acesso em: 25 mai. 2020.

ZANDONADE, Patricia. Mobilidade urbana e utilização energética: estudo dos padrões das metrópoles de São Paulo e Paris. 2012. Tese (Doutorado em Energia) - Universidade Federal do ABC, Santo André, 2012.

ZANDONADE, Patricia; AUTOR. 2012. Omitido para avaliação às cegas. 


\begin{abstract}
Sobre os autores:
Emanuel Ramos Cavalcanti

Graduação pela Universidade Federal do Ceará (2004), mestrado pela Universidade Federal de Pernambuco (2008) e doutorado pela Universidade Presbiteriana Mackenzie (2018) com período "sanduíche" de um ano no Instituto Superior Técnico de Lisboa. Professor substituto do Departamento de Arquitetura (DARQ) da Universidade Federal do Rio Grande do Norte (UFRN). Universidade Federal do Rio Grande do Norte - UFRN, Natal, RN, Brasil.

Lattes: http://lattes.cnpq.br/ 6805137553894905 Orcid: https://orcid.org/0000-0002-3131-7786

E-mail: emanuel.cavalcanti.au@gmail.com
\end{abstract}

\title{
Amíria Bezerra Brasil
}

Graduada em Arquitetura e Urbanismo (UFC - 2003). Doutora em Arquitetura e Urbanismo (USP - 2016). Docente do ensino superior do Departamento de Arquitetura da Universidade Federal do Rio Grande do Norte (UFRN). Membro do Observatório das Metrópoles Núcleo Rio Grande do Norte (RN). Universidade Federal do Rio Grande do Norte - UFRN, Natal, RN, Brasil.

Lattes: http://lattes.cnpq.br/ 8887892378979463 Orcid: https://orcid.org/0000-0001-6877-4916

E-mail: amiriabrasil@gmail.com

\section{Ricardo de Sousa Moretti}

Engenheiro civil, Mestre em Engenharia de Solos e Doutor em Engenharia de Construção Civil e Urbana pela SP. Foi pesquisador do IPT e professor do Mestrado em Habitação desta instituição. Trabalhou como professor e pesquisador na Arquitetura da PUC - Campinas e como professor visitante da UFRN. Professor titular da UFABC onde ingressou em 2007. Aposentado desde 2017, atualmente é professor colaborador do Programa de Planejamento e Gestão do Território da UFABC. Universidade Federal do ABC, Santo André, SP, Brasil Lattes: http://lattes.cnpq.br/7819421851048499 Orcid: https://orcid. org/0000-0002-3807-4684

E-mail: ufabc.moretti@gmail.com

\section{Julia Azevedo Moretti}

Mestre em Direito Urbanístico pela Pontifícia Universidade Católica de São Paulo (PUC/SP) e mestre em Meio Ambiente e Desenvolvimento Sustentável pela Universidade de Londres (Development Planing Unit - DPU/UCL). Doutoranda pela Universidade de São Paulo (USP), advogada popular e professora assistente no curso de specialização de Direito Contratual do COGEAE PUC/SP. Pontifícia Universidade Católica de São Paulo (PUC/SP), São Paulo, SP, Brasil

Lattes: http://lattes.cnpq.br/ 4735094906899872 Orcid: https://orcid.org/0000-0003-4898-1824

E-mail: moretti.julia@gmail.com

Os autores contribuíram igualmente para a redação do artigo. 